\title{
AN ELECTROCARDIOGRAPHIC STUDY OF FIFTY PATIENTS DURING OPERATION*
}

\author{
W. G. LENNOX, M.I). \\ PEKING, CHINA \\ R. C. GRAVES, M.D., ANi S. A. LEVINE, M.D. \\ BOSTON
}

For a thorough understanding of the action of the heart, it is important that it be studied under various conditions of stress. This investigation was undertaken to determine whether there are any abnormalities in the mechanism of the heart beat, demonstrable by electrocardiography, during the period of anesthetization and surgica! operation.

Heard and Strauss ${ }^{1}$ reported a case of atrioventricular rhythm detected electrocardiographically in a patient still under ether following an operation. They state, "no other cases of nodal rhythm have been observed by us in a series of twenty-one cases in which electrocardiographic records have been taken during anesthesia." Levine ${ }^{2}$ reported cases of acute cardiac upsets occurring in association with surgical operations. In two of his cases electrocardiographic tracings were made during attacks of paroxysmal auricular tachycardia while the patients were still under ether. These two reports were the only references to the subject found in the literature.

\section{MATERIAL AND METHODS}

This paper covers the study of fifty operations performed on forty-eight individuals on the surgical service of the Peter Bent Brigham Hospital during May and June, 1921. The cases were selected to the extent that the wiclest possible variety of conditions of age, type of anesthesia, cardiac condition, operative procedure, etc., were covered. They represent the more serious of the usual operative cases. The total time during which patients were under observation was seventy-five hours. During this period a total of 1,750 records were made. Electrodes of the type described by $\mathrm{Cohn}^{3}$ were applied and preliminary tracings made before the beginning of anesthesia. By

* From the medical and surgical clinics of the Peter Bent Brigham Hospital.

1. Heard, J. D., and Strauss, A. E.: An Electrocardiographic Study of Two Cases of Nodal Rhythm Exhibiting R-P Intervals, Am. J. M. Sc. 75:238, 1918.

2. Levine, S. A.: Acute Cardiac Upsets Occurring During or Following Surgical Operations, J. A. M. A. 75:796 (Sept. 18) 1920.

3. Cohn, A. E.: A New Electrode for Use in Clinical Electrocardiography, Arch. Int. Ned, 26:105 (July) 1920. 
means of an electric buzzer the anesthetist signaled to the electrocardiograph operator the moment at which anesthesia and operation were begun and ended, and also indicated any critical stages in the operation or in the patient's condition. By this means, tracings and operative procedures were correlated. Short records were made at intervals from the beginning of anesthesia until the time when the patient was ready to leave the operating table. On the average a tracing was made every two and one-half minutes. Graphic records were obtained for about 3 per cent. of the time the patients were on the table. The galvonometer string was watched for a much longer period than this, and any gross abnormality of rate or rhythm, lasting more than a few minutes, would have been detected. Most records were of Lead II, but occasionally, because of manipulations during operation in abdominal cases, it was recessary to use Lead I.

\section{HEART RATES}

The rate of the heart during operation is a matter of practical importance. Operators usually rely on the pulse rate as furnished by the anesthetist. In this study it was found that the heart rate, calculated from electrocardiographic tracings, in many instances was much higher than the count the anesthetist reported. The highest heart rate in this series was 217 beats per minute, occurring during the etherization of a child. The highest recorded pulse rate in this case was 180 . In seventeen cases, or 34 per cent., the heart rate was twenty or more beats per minute faster than the highest recorded pulse rate. In nine cases, or 18 per cent., this discrepancy amounted to thirty or more beats. The most marked difference was in the case of a girl, who held her breath during the early stages of etherization. Her heart and pulse rates are shown in Figure 1. Discrepancies occurred with equal frequency under ether and gas-oxygen anesthesia. In certain of these cases there may have been an actual pulse deficit. In others the discrepancy might be explained by the fact that the pulse rates taken at five minute intervals did not catch short rises in rate shown by the more frequent electrocardiographic readings. Again, the highest rates and the most marked discrepancies occurred usually during the induction of anesthesia, when the pulse rate was taken by a nurse from the ward. During the period of operation, a trained anesthetist took the readings, using the temporal artery.

These observations show that the anesthetist's chart of pulse rate cannot be taken, in many instances, as a record of heart rate. For those cases in which it is important that the operators have accurate information, the rate should be obtained from the apex beat. This is easily rone by strapping a stethoscope over the precordium, using tubing of sufficient length to reach the anesthetist. Another accurate method, 


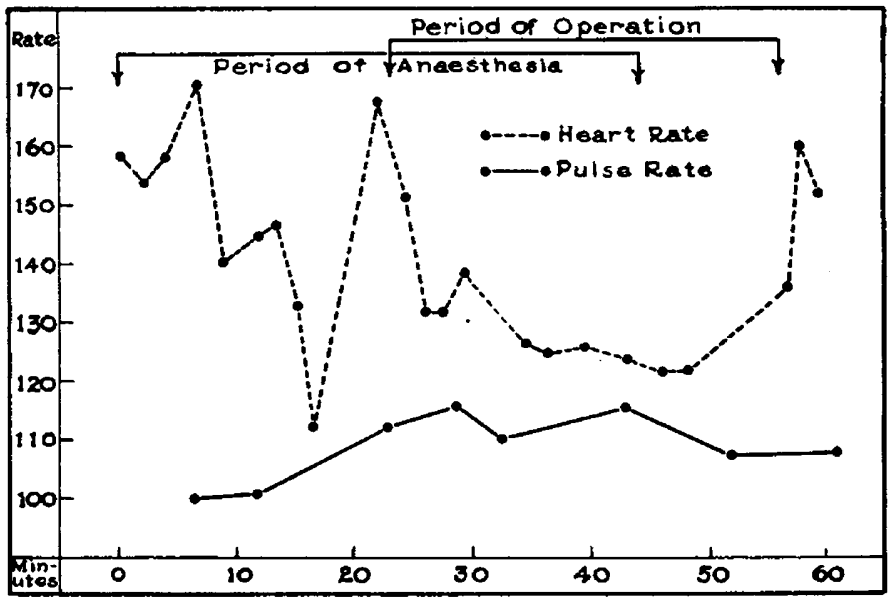

Fig. 1.- Upper line shows the heart rate as determined from electrocardiograms; lower line, the pulse rate as recorded by the anesthetist.

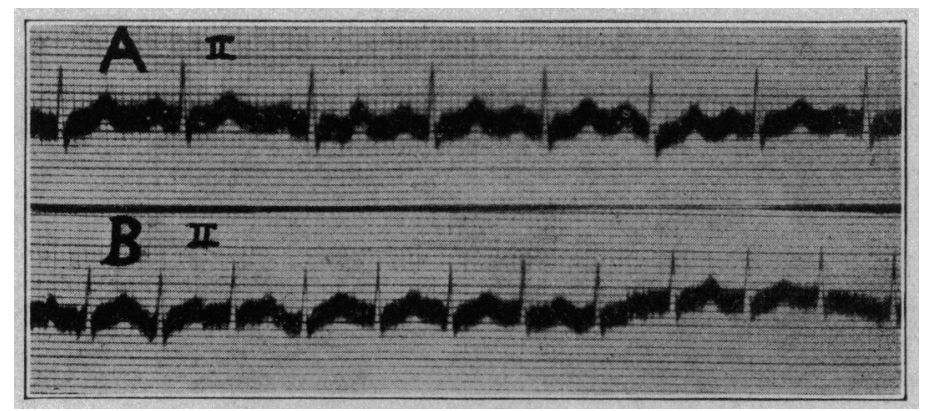

Fig. 2.-Case 7. Operation, fixation of uterus. A. Tracing taken twenty-six minutes after beginning of operation; rate 104, rhythm normal. B. Taken four minutes later than $\mathrm{A}$; rate 164 , paroxysmal tachycardia.

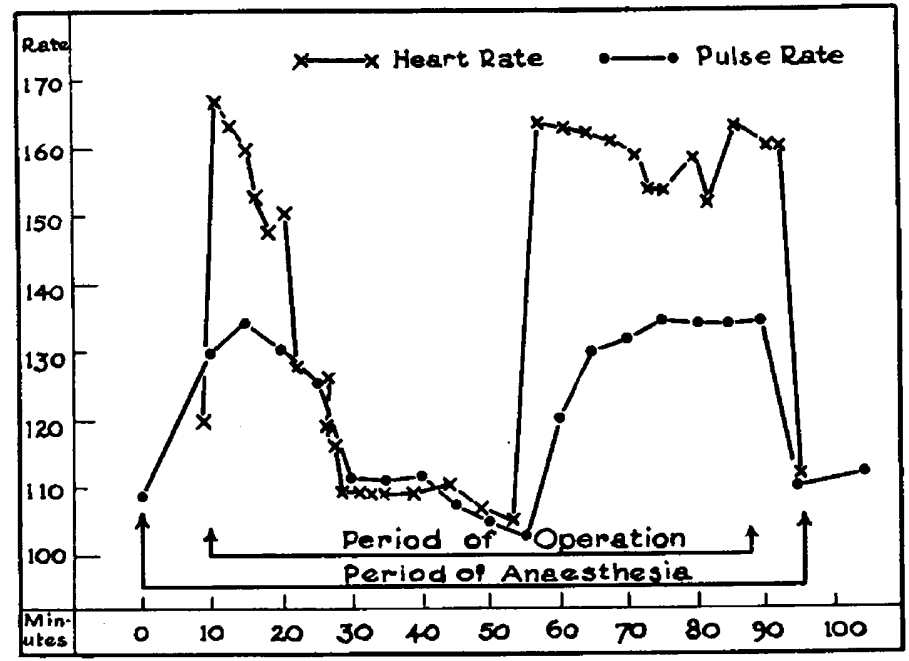

Fig. 3.-An instance of paroxismal tachycardia unsuspected by the operating staff. 
used in the head operations of this series, is to count the pulsations in the brachial artery as heard in the auscultatory method of obtaining blood pressure records.

\section{ABNORMALITIES OF RHYTHM}

Paroxysmal Tachycardia.-One patient, a woman, 80 years of age, showed this type of arrhythmia. The electrocardiogram appears in Figure 2, and the heart and pulse rates in Figure 3. The first sharp rise in rate, from 120 to 167 , occurred during the half minute or so required to change from one lead to another. Without the electrocardiograph, this abnormality would have gone unrecognized, for the anesthetist noted only a rise of pulse rate to 135 . The fast rate was unaccompanied by any adverse change in the patient's condition.

Premature Beats.-In eleven cases, premature beats were recorded. They were ventricular in origin in seven cases, and auricular in four. It should be stated, however, that two of the eleven showed premature beats in the preliminary tracings and in another there was a clear past history of premature systoles. One case which showed paroxysmal auricular tachycardia and premature beats on entrance to the hospital, ten days before operation, showed no abnormality during operation. During the ten day interval he had been on digitalis. The records of eight of the eleven cases showed only one or two premature beats. In two cases, premature beats occurred for short periods as often as every third beat. In none did the anesthetist note the irregularity. The time relations of the premature beats to the operation are shown in the upper part of Figure 4.

Sinus Arrhythmia.-The occurrence of well marked sinus arrhythmia was noted in three cases.

\section{DISTURBANCES IN CONDLCTION}

Delayed auriculoventricular conduction, with a lengthening of the $P$ - R interval from 0.2 to 0.24 second, occurred in one patient during an operation for the ligation of a thyroid artery. Krumbhaar ${ }^{4}$ reported forty-seven cases of toxic goiter in which tracings were taken before and after operation; two of these showed a delay in conduction time after operation. In regard to disturbances in the branches of the conduction apparatus, it is worthy of note that in our series, no case showed a prolongation of the QR $\mathrm{R}$ interval. One case showed a widened $Q R S$ complex $(0.1$ second $)$ in the preliminary tracing, but it did not increase during the operation. The patient died eight days later from bronchopneumonia and pulmonary embolism.

4. Krumbhaar, E. B.: Electrocardiographic Observations in Toxic Goiter, Am. J. M. Sc. 155:175, 1918. 
There was no evidence of heart failure, but at the necropsy an area of fibrous myocarditis $1 \times 2 \mathrm{~cm}$. in size was found in the wall of the left ventricle.

\section{DISLOCATION OF THE PACEMAKER}

The chief interest of the study was found to lie in the frequent displacement of the cardiac pacemaker, as evidenced by changes in the shape, direction and position of the $\mathrm{P}$ wave (auricular complex). Fifteen of the cases, or 30 per cent., showed some variation in the

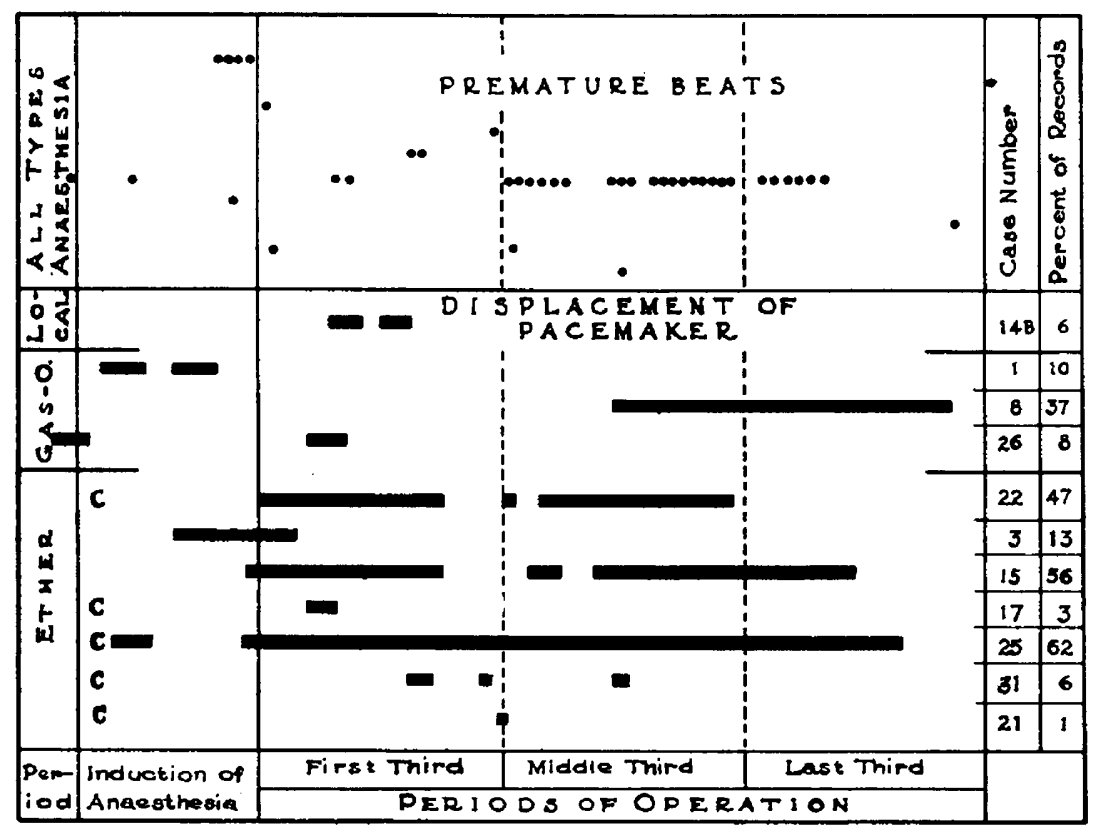

Fig. 4.- The chart illustrates the period during which premature beats and displacement of the pacemaker occurred. The upper portion is for the ten cases which showed premature beats. Each dot represents one such beat. The lower portion is for the eleven cases which showed marked abnormalities of the $\mathrm{P}$ waves. They are grouped according to the anesthetic used. In the ether group the letter $\mathrm{C}$ indicates those receiving ether by the Connell apparatus. On the right the first column of figures gives the case number and the second column the percentage of records which showed the abnormal rhythm. The length of the black line is, in each case, a rough measure of the percentage of records which showed the abnormality.

$P$ wave not present in the preliminary tracings. In three of the cases, the abnormality consisted only in a shortening of the $P-R$ interval of 0.04 second or more. This shortening was not due to an increase in rate. In one of the cases there was only a flattening of the $\mathrm{P}$ waves. Various explanations for such flattening have been discussed by Wil- 
son, ${ }^{5}$ e. g., diminution in contractility of auricles, interference of two rhythms, changes in the path of the contraction wave over the auricles and changes in the location of the pacemaker. In the remaining eleven cases the tracings showed more marked variations of the auricular

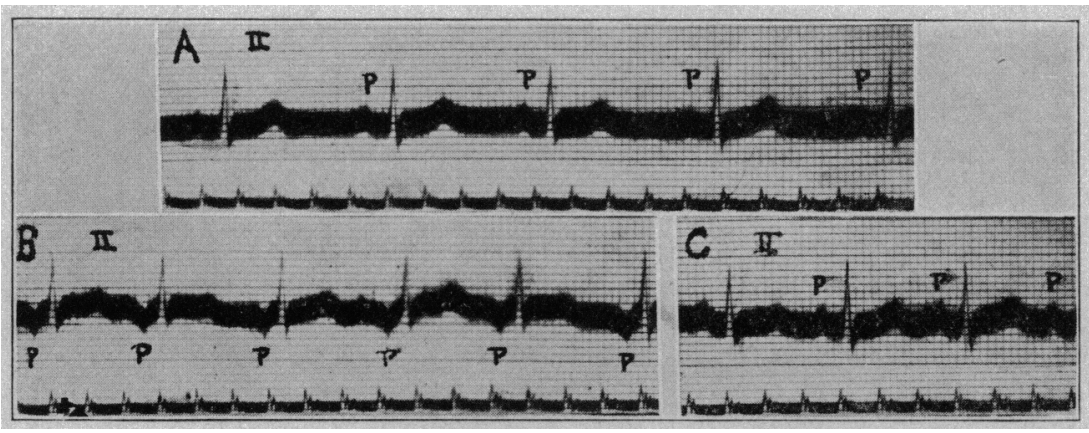

Fig. 5.-Case 17. Operation, tonsillectomy. Lead II. A. Normal tracing. rate 68 . $P-R$ interval $0.16 \mathrm{sec}$. Taken at signal for first incision. B. Inverted $P$ waves, rate 94 . $P-R$ interval 0.12 sec. Taken two minutes after $A$. C. Normal tracing, rate 59 . Taken one minute after $\mathrm{B}$.

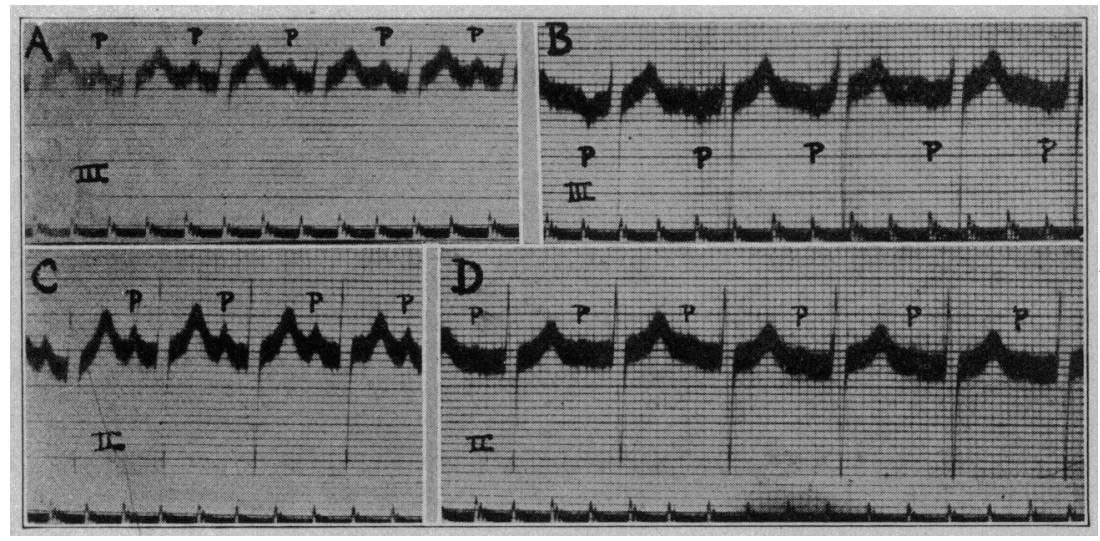

Fig. 6.-Case 21. Operation, arulsion trigeminal ganglion. A. Lead III, normal tracing, rate 121 . $P-R$ interval $0.16 \mathrm{sec}$. $B$. Lead III inverted $P$ waves, $\mathrm{P}-\mathrm{R}$ interval $0.12-0.16 \mathrm{sec}$; rate 101 . C. Lead II normal tracing; rate $140 . \mathrm{D}$. Lead II P waves greatly flattened; rate 107 . Taken two minutes previous to $C$.

complex, i. e., either an absence of the wave, or an inverted $P$ wave with diminished $P-R$ interval, or even the $P$ wave following the $\mathrm{R}$ wave, producing an $\mathrm{R}-\mathrm{P}$ interval.

5. Wilson, F. N.: Three Cases Showing Changes in the Location of the Cardiac Pacemaker Associated with Respiration, Arch. Int. Med. 16:86 (July) 1915. 
Following the classification used by Wilson ${ }^{6}$ in reporting his cases of $\mathrm{A}-\mathrm{V}$ rhythm which resulted from the injection of atropin, these eleven cases are divided into three groups:

1. Cases in Which the "P" Wave Is Inverted and the P-R Interval Reduced.-Three of the patients showed this abnormality. In Figure 5, three successive records are shown. The first was taken on the signal denoting the beginning of operation (tonsillectomy), the second, which shows inverted $\mathrm{P}$ waves, two minutes later, and the last one minute after the second. The rate of the heart in the middle (abnormal) record is intermediate between the rates of the other two. Figure 6, from another case, is of interest in that it shows in one lead at one time an inverted " $\mathrm{P}$," and in another lead at another time a markedly flattened "P."

2. Cases in Which the "P" Ware Is Absent.-Seven of the cases showed a disappearance of the $\mathrm{P}$ wave. Examples from three of these are shown in Figures 7,8 and 9. In Figures 7 and 8 there is in some of the cycles a slight irregularity of the auricular complex, suggesting an interference of two rhythms. In some instances interpretation was difficult because of the artefacts produced by the operative procedures. Figure 8 is of particular interest for its shows the onset of the abnormal rhythm. Here the transition occurs abruptly, without preliminary shortening of the $\mathrm{P}-\mathrm{R}$ interval, but with slight slowing of the rate. In Figure 9 (C) a condition of auriculoventricular dissociation probably exists, the auricle responding to the sinoauricular node and the ventricle to the auriculoventricular node. In two of the seven cases, in addition to records showing absent $\mathrm{P}$ waves, there are other records showing inverted $\mathrm{P}$ waves.

3. Cases in Which the "P" Wave Is Inverted and There Is an $R-P$ Interval.-One case belonged to this group. Figure $10(\mathrm{~B})$ shows the established abnormal rhythm with the heart responding to but one pacemaker. Figure 11 from the same case shows the onset of abnormal rhythm, the P-R interval becoming shorter and shorter until the $\mathrm{P}$ wave is lost in the $R$ wave. In this tracing, as in Figure 9 (C), there is a mixed rhythm, the heart responding to two pacemakers. The transition is accompanied by a slight decrease in rate. The operation was the excision of a right cervical rib in a young woman. The operator "neither saw nor touched the vagus nerve."

In addition to the above group of eleven cases, there was one patient whose tracings showed bigeminy and marked differences of the $P$ wave in successive cycles. As his control tracings, both before and after operation, showed the abnormality this case is not included in the

6. Wilson, F. N.: The Production of Atrioventricular Rhythm in Man After the Administration of Atropin, Arch. Int. Med. 16:994 (Dec.) 1915. 


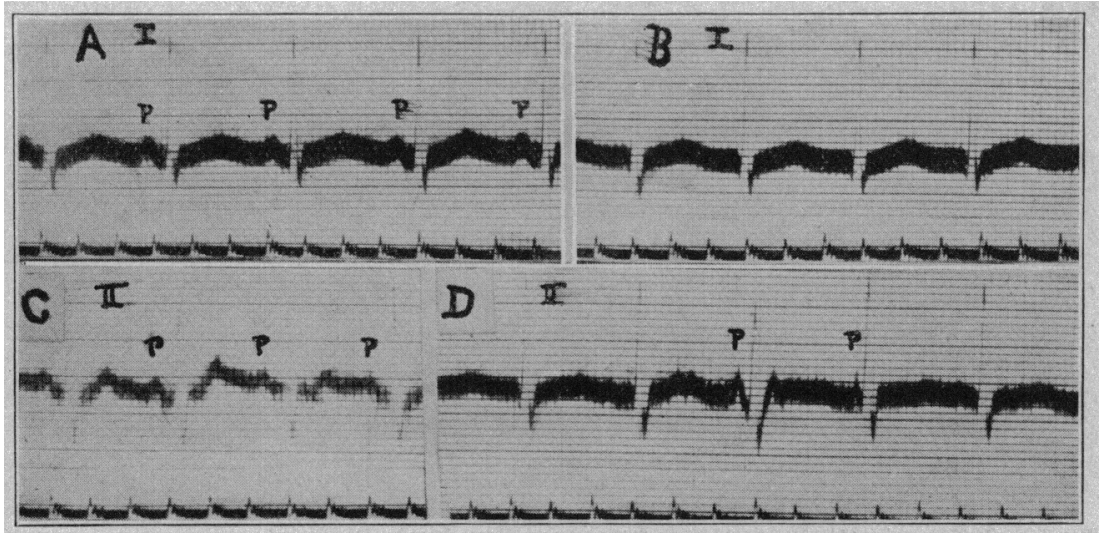

Fig. 7.-Case 25. Operation, excision tumor of cerebrum. A. Lead I, normal tracing; rate 93 . B. Lead $\mathrm{I}$, absent $\mathrm{P}$ waves; rate 103 . C. Lead II, normal tracing; rate 108 . Taken seven minutes after beginning of anesthesia. $D$. Lead II, $P$ waves are in some cycles absent, in others the P-R interval is much diminished; rate 107 .

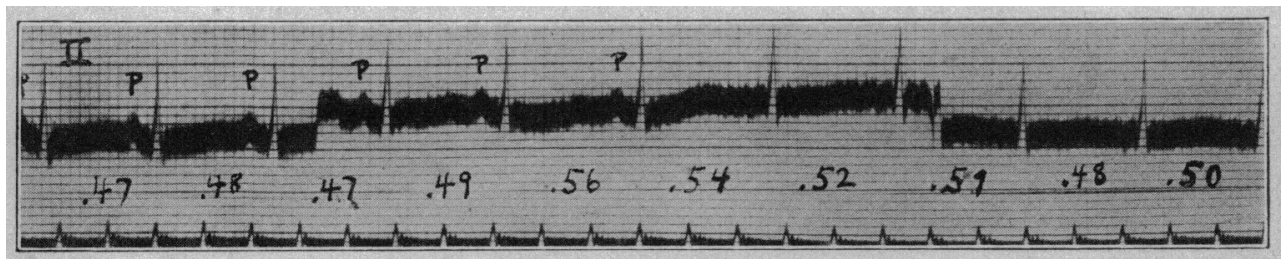

Fig. 8.-Case 31. Operation, cerebellar exploration. Lead II. Note disappearance of $\mathbf{P}$ waves with slight decrease in heart rate. Figures indicate length of heart cycles.

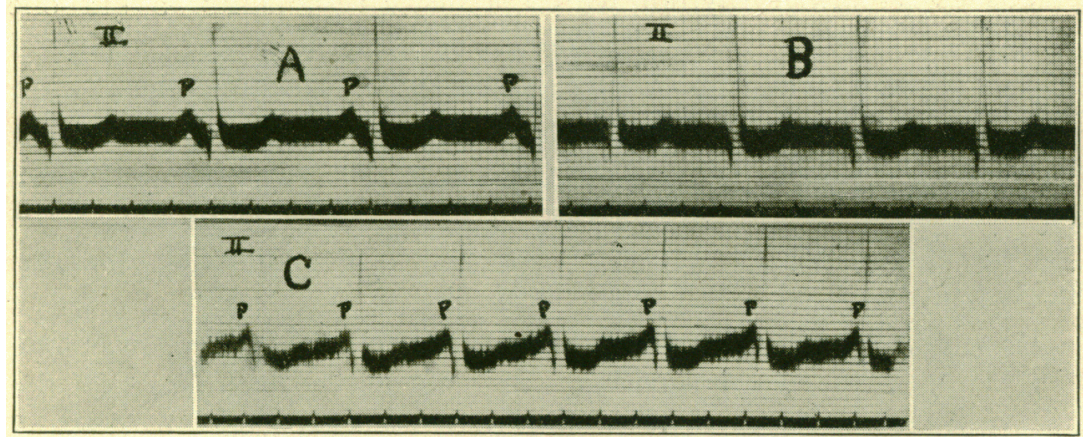

Fig. 9.-Case 1. Operation, suprapubic prostatectomy. Lead II. A. Normal tracing; rate 74 . B. Absent $P$ waves; rate 94 . Taken three minutes after beginning of anesthesia. C. P-R interval diminished, $P$ upright; rate 110. Taken three minutes after $B$. 
preceding group. One of the eleven cases showed a single record with inverted $\mathrm{P}$ waves just before the beginning of anesthesia. Aside from the constantly abnormal case mentioned above, this is the only instance in the series of fifty cases of a disturbance of the pacemaker occurring in any of the control tracings taken before and after operation. In all cases the abnormality had disappeared before the patient left the operating table. Records were taken during convalescence of several

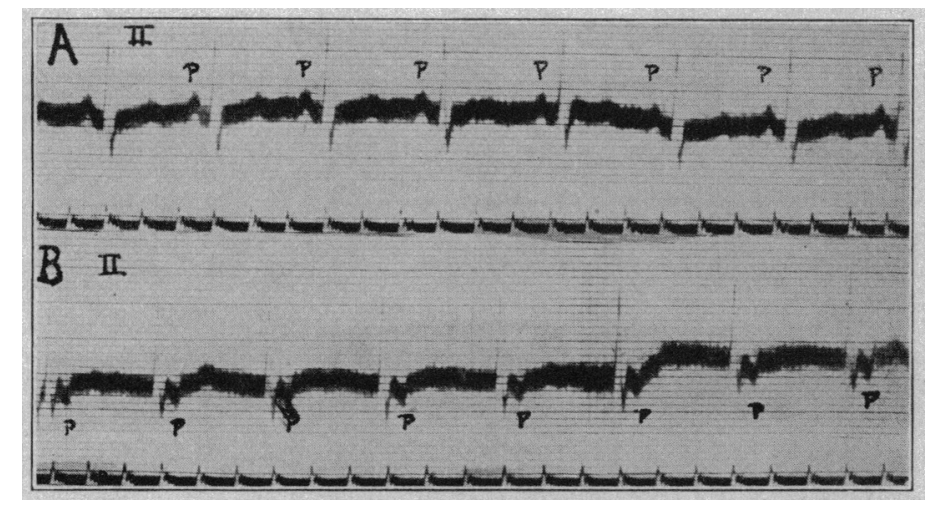

Fig. 10.-Case 22. Operation, excision cervical rib. Lead II. A. Normal tracing; rate 99 . Taken at time of first incision. B. Inverted $P$ waves, $R-P$ interval of $0.08 \mathrm{sec}$; rate 99 . Taken one minute after $\mathrm{A}$.

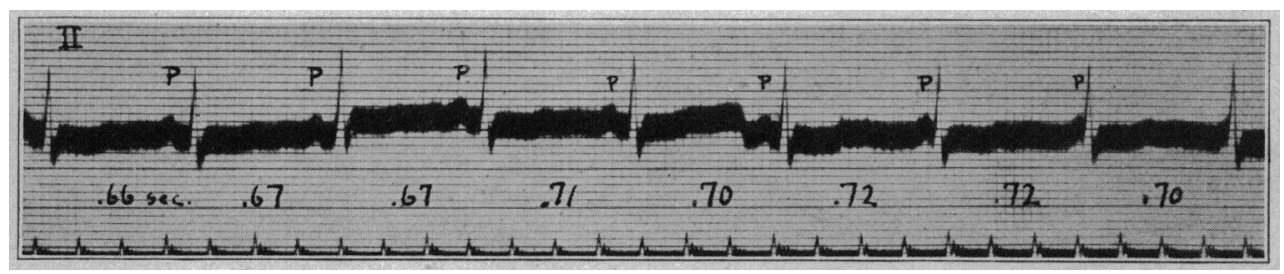

Fig. 11.-Case 22. Lead II. Onset of abnormal rhythm. $P$ is upright, the $\mathrm{P}-\mathrm{R}$ interval progressively diminishing, with slight decrease in rate. Figures indicate length of heart cycles.

patients who had shown abnormality of $\mathrm{P}$ waves during operation. All were found normal. Two of the fifty cases showed auricular waves which were, in some of the tracings, considerably larger than the normal $\mathrm{P}$ waves for those individuals.

Significant variations in the height of the $\mathrm{R}$ or $\mathrm{T}$ waves, other than a transient inversion of a low $\mathrm{T}$ wave in one case, were not noted.

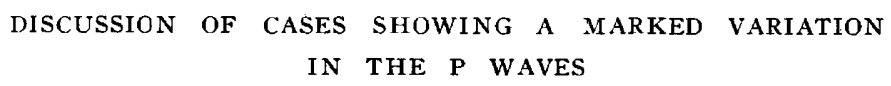

In the preceding section we have sought to present graphic records of abnormalities rather than their interpretation. The question now 
arises as to how many of these are examples of $\mathrm{A}-\mathrm{V}$ (atrioventricular) rhythm. A large proportion of such cases would not be inconsistent with experimental findings. Levine, ${ }^{7}$ while taking electrocardiographic records of etherized cats, about every six minutes, found that in fourteen out of forty-seven experiments, tracings showed the presence of $A-V$ rhythm. In almost all instances the abnormal rhythm appeared after the etherization of the animal but before the beginning of the experiment (intravenous injection of strophanthin).

There are difficulties, however, in the way of interpreting all these abnormal tracings in the present study as instances of $\mathrm{A}-\mathrm{V}$ rhythm. In the first place, there is in the literature a lack of unanimity in the definition of this condition. Should the term be confined to those cases of pure $A-V$ rhythm in which the heart is responding to but one pacemaker located in the $A-V$ node, or should it include cases of mixed or double rhythm in which impulses arise from both the S-A (sinoauricular) and $A-V$ nodes? There is a difference of opinion concerning the criteria by which $\mathrm{A}-\mathrm{V}$ rhythm is to be diagnosed from electrocardiographic tracings. Some writers consider it essential that the $\mathrm{P}$ wave be inverted. On the other hand, the statement appears in a recent paper that in $\mathrm{A}-\mathrm{V}$ rhythm the $\mathrm{P}$ wave is frequently though by no means constantly inverted. ${ }^{8}$ Carter and $W e d d,{ }^{9}$ in reporting twelve cases of inverted $\mathrm{P}$ in Lead III, consider that a transient inversion of $\mathrm{P}$ means a displacement of the pacemaker.

Furthermore, in those cases showing $P$ waves, it is a point of issue as to how much shortening of the P-R interval there must be in order to prove that the impulse arises in the $A-V$ node rather than in the auricular tissues adjacent to it. Theoretically, there should be a shortening in the P-R interval of at least 0.03 second, the time consumed by the impulse in passing from the $\mathrm{S}-\mathrm{A}$ to the $\mathrm{A}-\mathrm{V}$ nodes. ${ }^{10}$ Confusing factors may, however, enter in. Thus, in the presence of vagal stimulation depressing $\mathrm{A}-\mathrm{V}$ conduction, there may be, coincident with the descent of the pacemaker, a lengthening of the P-R time. ${ }^{11}$

In the tracings in which the $\mathrm{P}$ wave does not appear and is buried in the $Q \mathrm{R} \mathrm{S}$ (ventricular) complex, it is not always clear whether

7. Levine, S. A.: The Action of Strophanthin on the Living Cat's Heart, J. Exper. M. 29:493, 1919.

8. Barker, L. F., and Richardson, H. B.: An Unusual Combination of Cardiac Arrhythmia of Atrial Origin Occurring in a Patient with Focal Infection and Thyroid Adenomata, Arch. Int. Med, 23:158 (Feb.) 1919.

9. Carter, E. P., and Wedd, A. M.: Observations on the Occurrence of inverted and Diphasic P Waves in Lead III of the Human Electrocardiogram, Arch. Int. Med. 23:16 (Jan.) 1919.

10. Lewis, T.: The Mechanism and Graphic Representation of the Heart Beat, New York, Paul B. Hoeber, 1920, p. 189.

11. White, P. D.: Clinical Observations on Unusual Mechanisms of the Auricular Pacemaker, Arch. Int. Med. 25:423 (March) 1920. 
the unseen $\mathrm{P}$ is upright or inverted. Again, an apparently absent $\mathrm{P}$ wave may mean that it has become so greatly flattened in that particular lead as to be isoelectric, though it might appear as a distinct wave in another lead. Another possibility when the auricular complex is absent is standstill of the auricle, described by White. ${ }^{12}$

A further consideration is the lead in which the abnormality appears, for inversion of $P$ in Lead III is not so significant as inversion in Lead II. In tracings made on 700 cases, mostly cardiacs, Goddard ${ }^{13}$ found inversion of $P$ in Lead III seventy-five times and in Leads I and II only eleven times. Barker and Richardson, ${ }^{8}$ on the other hand, among 400 records found but one showing inverted $P$ waves. In the eleven cases of variation of $\mathrm{P}$ waves in this study, all but two showed the abnormality in Lead II.

Because the disturbances in this series were transient and the patients were being operated upon, there was no opportunity for experimentation on the effects of atropin, vagal pressure, etc. We did not have, as did Wilson in his report of $\mathrm{A}-\mathrm{V}$ rhythm occurring after the injection of atropin, the benefit of simultaneous venous tracings. It would appear certain, however, that all these cases represent various stages of the same process, viz., a dislocation of the pacemaker. (In the cases of auricularventricular dissociation ${ }^{14}$ one might more properly speak of a doubling of the pacemakers.) In most of the cases, possibly in all, the pacemaker, or where there are two, one of the pacemakers arises in the $A-V$ node. Because we cannot be certain that all of these are cases of $A-V$ rhythm, we shall designate them simply as the group showing a marked dislocation of the pacemaker.

HEART RATES IN RELATION TO DISLOCATION OF THE PACEMAKER

Dislocation of the pacemaker is explained on the theory either that the rate of the $\mathrm{S}-\mathrm{A}$ node falls below that of the $\mathrm{A}-\mathrm{V}$ node, in which case the latter becomes the pacemaker, or that the $A-V$ node is stimulated to a rate above that of the $\mathrm{S}-\mathrm{A}$ node. In either instance the rates during normal and abnormal rhythm might differ. The heart rates for cases showing dislocation of the pacemaker were charted and found to fall into three classes. Four cases showed a slower rate during the abnormal rhythm. The heart rate of one of

12. White, P. D.: Auricular Standstill, an Unusual Effect of Digitalis on the Heart with Special Reference to the Electrocardiograph, Boston M. \& S. J. $175: 233,1916$.

13. Goddard, C. H.: Changes in the P Wave of the Human Electrocardiogram, Arch. Int. Med. 16:133 (July) 1915.

14. White, P. D.: Ventricular Escape with Observations on Cases Showing Ventricular Rate Greater than that of the Auricles Arch. Int. Med. 18:244 (Aug.) 1916. 
these is illustrated in Figure $12 \mathrm{~A}$. Here after the beginning of operation, whenever the heart rate fell to 125 or below there was an absence of $\mathrm{P}$ waves in the electrocardiographic record. In one instance, the heart rate was faster during the period of abnormal rhythm (Fig. $12 \mathrm{~B}$ ). In six of the cases, the rate bore no relation to rhythm. This group is illustrated (Fig. 13) by the case which showed on R-P interval. As seen in the chart, the rhythm changed on three occasions without a change in rate.

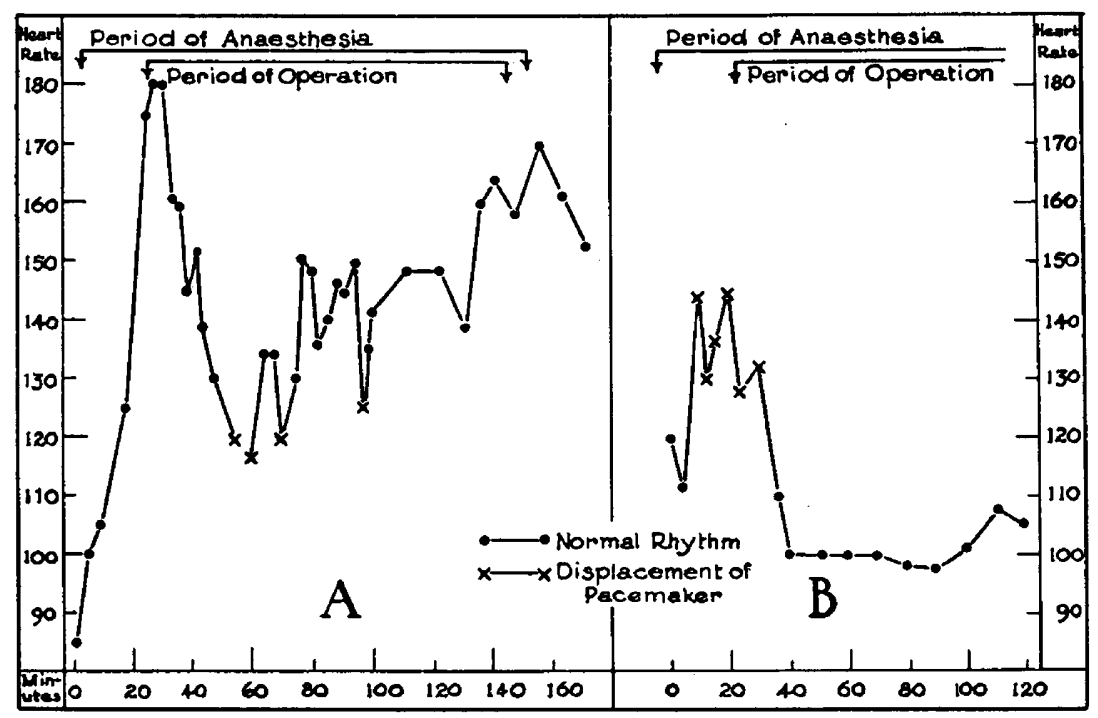

Fig. 12.-A. Note the slower rate which occurs with the displacement of the pacemaker. B. Note the faster heart rate which occurs with the displacement of the pacemaker.

\section{FACTORS IN PRCDUCTION OF ABNORMALITIES}

In discussing the cause of the abnormalities noted, it is necessary to consider various factors. Twenty-four ( 48 per cent.) of the cases show some disturbance of the heart beat not present in the preliminary tracings. Eleven of these are classified as showing displacement of the pacemaker (some show other changes as well); thirteen as showing other abnormalities. The number of cases is too small and the factors concerned are too numerous to permit definite conclusions. The following analyses must therefore be regarded simply as interesting observations.

Sex.-Twenty-three of the persons operated on were males, and twenty-five were females. Sex bore no relation to the incidence of abnormality. 
$A g c$.- The age of patients varied from 2 to 84 years. Twenty-six were under 40 while twenty-two were over 40 years. The incidence of abnormality for those under 40 was nearly the same as for those over that age.

Cardiovascular Symptoms.-A history of serious infection (scarlet fever, rheumatic fever, chorea, tonsillitis, pneumonia, etc.) was not more common in those yielding abnormal tracings than in the normal group. A history of cardiac symptoms (dyspnea, edema, etc.) was, on the other hand, of some importance. Only 11 per cent. of those with normal tracings gave a story of cardiac disturbances, whereas 41 per cent. of those with abnormal tracings reported such difficulties.

Cardiac Lesions.-Only four of the forty-eight persons showed definite signs of cardiac disease by routine physical examination. Two

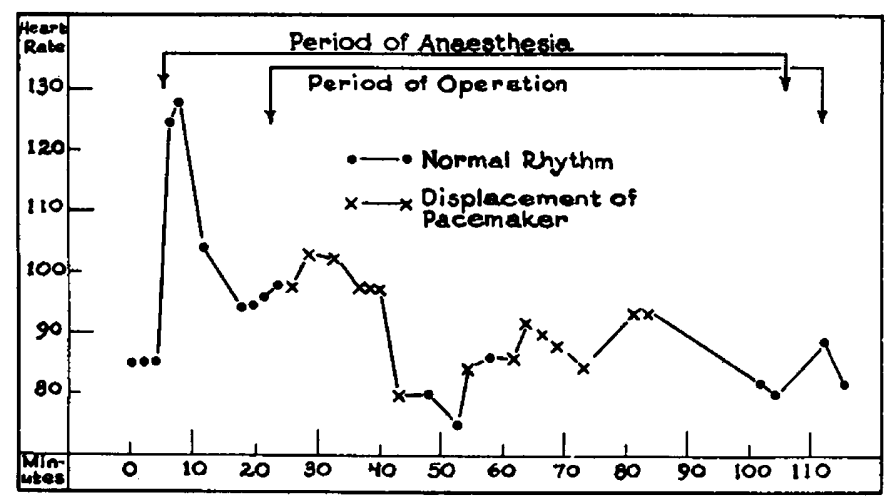

Fig. 13.-Note that a change of rhythm occurs in three instances without a change of rate.

of these (one a case of mitral stenosis and the other of chronic myocarditis) showed abnormal preliminary tracings and the other two (one a case of mitral regurgitation and the other of sclerotic aortic valves) showed some abnormality during operation. In only one case did the condition of the heart cause serious debate as to the advisability of operation. This was a woman with a permanent auricular fibrillation and mitral stenosis who had had repeated attacks of gallstone colic. She was thoroughly digitalized so that on the morning of operation there was no pulse deficit. In order to determine whecher a pulse deficit occurred during operation, the anesthetist signaled the times at which she counted the pulse, and simultaneously electrocardiographic records were made. During the period of induction of anesthesia the auricular impulses broke through the digitalis block and the heart rate jumped to 150 , while the pulse rate dicl not exceed 100 . In this instance there 
was without doubt a real pulse deficit. During the period of actual operation, however, there was no deficit. Cholecystectomy was performed without any difficulty and the patient left the hospital in satisfactory condition.

Blood Pressure.-With due consideration to the age of the patients, five of forty-five patients had high blood pressures, and nine had pressures which seemed to be low. Abnormality of blood pressure in this series bore no relation to abnormality of the heart mechanism.

Position During Operation.-Normal records were obtained more frequently in those patients who were placed flat on the table than in those in other positions. It is probable, however, that other factors were operative in these cases.

Preliminary Medication.-Thirty-seven of the patients received preliminary morphin (usually $0.01 \mathrm{gm}$.) and atropin (0.0005 gm.). Seven received morphin only and six had no preliminary medication. Wilson ${ }^{6}$ has shown that for from eight to fifteen minutes following the injection of $1 \mathrm{mg}$. atropin, vagal stimulation produced an $\mathrm{A}-\mathrm{V}$ rhythm in the majority of his twenty cases. The abnormal rhythm could not be produced after twenty minutes had elapsed. In this series the atropin would not be expected to cause $A-V$ rhythm, for the dose was only one half that used by Wilson and at least thirty minutes intervened before the beginning of the observations. Of the thirty-seven cases receiving atropin, six ( 16 per cent.) showed a disturbance of the pacemaker; of the thirteen cases not receiving atropin, five (38 per cent.) showed this change. The preliminary atropin would seem to diminish rather than increase the chances of inducing the abnormal rhythm. Concerning morphin, Cohn ${ }^{15}$ has shown in dogs that the action of the drug is similar to vagus stimulation. In our forty-four cases receiving morphin, however, eight patients had disturbances of the pacemaker, while of the six not receiving it, three showed these changes. The observations are too few to warrant any conclusions as to the role that morphin may play in the production of abnormalities.

Lack of Oxygen.-The work of Greene and Gilbert ${ }^{16}$ suggests that anoxemia may be a factor in producing $A-V$ rhythm; for, of their twenty-one soldiers who breathed air having a low oxygen tension, six showed this disturbance. In none of our cases was there any apparent lack of oxygen, although the routine anesthetization in the operating room did not provide any accurate data on this point.

Type of Anesthesia.-All of the anesthesias were given by one of a staff of three trained anesthetists. Twenty of the patients received

15. Cohn, A. E.: The Effect of Morphin on the Mechanism of the Dog's Heart After Removal of One Vague Nerve, J. Exper. M. 18:715, 1913.

16. Greene, C. W., and Gilbert, N. C.: Studies on the Responses of the Circulation to Low Oxygen Tensions, Arch. Int. Med. 27:517 (April) 1921. 
ether, thirteen by the open drop method and seven through an intrapharyngeal tube, using the Connell apparatus. Twenty-two had nitrous oxid and oxygen, and eight had local anesthesia (procain). The abnormal rhythm occurred in seven (35 per cent.) of the cases receiving ether, in three (14 per cent.) of those receiving gas-oxygen and in one (12 per cent.) of those who had procain. It was present in but 15 per cent. of the cases in which ether was given by the drop method but occurred in 70 per cent. (five out of seven) of the cases in which ether was given by means of a nasal tube introduced into the pharynx. Considering all forms of disturbances of the heart mechanism, abnormalities were not more common with one kind of anesthesia than with another.

Length of Anesthesia and Operation.-The longest period of anesthesia was three hours and five minutes and the shortest twentytwo minutes, the average being eighty-five minutes. Abnormalities were more frequent in the longer procedures than in the shorter ones.

Type of Operation.-The distribution of operative fields was as follows : head, six; throat and neck, seven; chest, one; intra-abdominal, nineteen; extraperitoneal, eleven; extremities, six. The chief differences were noted between operations involving the head and neck and those on other parts of the body. Of the former, 70 per cent. showed some type of abnormality in the electrocardiograph record, while of the latter 40 per cent. were abnormal. The fact that head operations were longer than those of other types does not account for this greater incidence of abnormalities, because abnormalities occurred in almost every case during the early part of the operation. A disturbance of the pacemaker was present in 46 per cent. of the thirteen operations involving the region above the clavicles, and in only 13 per cent. of all other operations. In several instances abnormality seemed to follow critical steps in the operative procedure, but in the great majority of cases no such relationship was evident.

Frequency of Records.-In five of the eleven cases of disturbance of the pacemaker, the abnormality appeared in one or two records only. It is possible, therefore, that other cases presented abnormalities of which records were not obtained. For all those cases showing abnormality, the interval of time between records is the same as for those showing no abnormality.

Time of Occurrence.-Figure 4 presents the time relations for cases showing premature beats (upper part) and disturbances of the pacemaker (lower part). In every instance except one the abnormal rhythm appeared during either the induction of anesthesia or the first third of the operation. This points to factors other than fatigue as a cause of this abnormality. 
In reviewing the evidence in this study it seems that the incidence of a displacement of the pacemaker is greater in patients having head and neck operation, intrapharyngeal anesthesia, or when preliminary atropin is omitted. It is possible that vagal stimulation is in some way concerned in these procedures. The production of premature beats does not seem to be clearly related to any of the factors considered. None of the cases showing abnormal electrocardiograms gave clinical evidence during operation of an embarrassed circulation. Though abnormality in the mechanism of the heart beat occurred with surprising frequency, these periods were transient and of physiological rather than clinical significance. ${ }^{17}$

\section{SUMMARY}

An electrocardiographic study of fifty cases was made during anesthesia and surgical operation.

1. In many cases the electrocardiographic tracings revealed a heart rate considerably faster than the pulse rate recorded by the anesthetist.

2. About one half of the cases showed some abnormality of the mechanism of the heart beat, not present in preliminary tracings, the most prominent being: paroxysmal auricular tachycardia; premature beats, and marked displacement of the cardiac pacemaker.

3. Various factors which might contribute to the production of the abnormalities named are analyzed. Only those which might possibly be concerned with alterations in vagal tone, seem to be of importance.

4. The observed abnormalities of the heart beat were transient and unassociated with clinical signs of embarrassed circulation. In the main, they were of physiological rather than of clinical significance.

We wish to thank Dr. Harvey Cushing and his associates, as well as the staff of the operating room, for their generous cooperation in this study.

17. A table giving detail of cases appears in authors' reprints. 